\title{
Spatial analysis and hazard assessment of mercury in soil around the coal-fired power plant: a case study from the city of Baoji, China
}

\author{
Xinwei Lu $\cdot$ Xiaopeng Yang $\cdot$ Lingqing Wang
}

Published online: 15 August 2007

(C) Springer-Verlag 2007

Erratum to: Environ Geol

DOI 10.1007/s00254-007-0747-1

Unfortunately the first author name was missing in the online version. The exact information of authors should be as follows:

Xinwei Lu $(\bowtie) \cdot$ Xiaopeng Yang $\cdot$ Lingqing Wang

College of Tourism and Environment, Shaanxi Normal University, Xi' an 710062, China

e-mail: lingqing054@stu.snnu.edu.cn

The online version of the original article can be found under doi:10.1007/s00254-007-0747-1.

\section{Yang}

Department of Mathematics, Physics and Engineering,

Shaanxi Institute of Education, Xi' an 710061, China

X. Lu $(\bowtie) \cdot X$. Yang $\cdot$ L. Wang

College of Tourism and Environment,

Shaanxi Normal University, Xi' an 710062, China

e-mail: lingqing054@stu.snnu.edu.cn 